\title{
Factor Affecting the Growth and Continuity of Micro and Small Enterprise in Robe Town
}

\author{
Melese Chala Tadesse \\ Department of Management College of Business and Economics ,Madda Walabu University,Bale Robe,Ethiopia
}

\begin{abstract}
Micro and Small Enterprises (MSEs) play an important economic role in many countries and recognized as an important vehicles of economic diversification, employment creation, income generation and distribution, and poverty alleviation. MSEs occupy a prominent position in the development agenda of many developing countries like Ethiopia. Currently, In Ethiopia, the Government has been promoting the development of MSEs through the formulation and implementation of Micro and Small Enterprises development strategy and the number of MSEs in the country is steadily growing. But, much more important than increase in their numbers, their current status, stage and pace of development is significant because most MSEs are hibernated from growing and faced with the threat of failure due to many factors. The purpose of this study is to assess the constraining factors related to marketing, management, finance and government supports hindering the growth of MSEs in Robe town. The study was employed through descriptive and explanatory research design in which stratified random sampling method was used to collect data from MSEs owners/ managers of five selected sectors according to the objective of the study with a total population of 949 and 281 samples. The samples were selected randomly from each stratum using proportionate allocation after stratification of the sectors. Questionnaires of data collection were used in the study. The data was analyzed using descriptive statistics and explanatory research design. The findings indicate that the most common factors constraining the growth of MSEs in Robe are: lack of working premises, lack of working capital and access to credit, lack of market access, inadequate availability of infrastructure, lack of managerial training and experience; and scanty of marketing information. Replication of this study using larger samples and a broader geographic base, longitudinal data collection and using more statistical tests is suggested for cross-validation purposes in future researches to identify the factors constraining the growth and survival of MSEs.
\end{abstract}

Keywords: growth, continuity, micro and small enterprise, Robe town

DOI: $10.7176 / \mathrm{EJBM} / 12-16-03$

Publication date:June 30th 2020

\section{Introduction}

The concept of MSEs has been defined and used differently in different countries. This reveals the absence of one universally accepted definition of (MSEs). In most cases, MSEs are defined based on the number of people employed in the enterprises, investment outlay, and annual sales turnover, paid up capital or a combination of these measures (Stephen \&Wasiu, 2013).

In Ethiopia, according to the new MSEDSE (2011), the previous definition was revised as "Micro Enterprise" consist of the number of its employees (including the owner or family) is not greater than 5 and total asset is less than 100,000 ETB for industrial sector and less than 50,000 ETB for service sector; while Small Scale Enterprise is an enterprise which has 6-30 employees and total asset 100,001-1,500,000 ETB for industrial sector and 50, 0001-500,000 ETB for service sector.

In many countries, nowadays there is a varied recognition of the contribution of Micro and Small Enterprises (MSE) to economic growth; recently the role of MSE in economic growth, urban poverty reduction and employment creation have engaged most of the discussions among government, policy makers and academicians. Wolde and Geta (2015) in their research paper stated that in most fast developing countries MSE by virtue of their size, location, capital investment and their capacity to contribute for urban poverty reduction and generate greater employment have proved their powerful effect for rapid economic growth.

Currently, MSEs in both developed and developing countries are seen as the most important alternative sector in fostering socio-economic developments. Particularly, they make undoubtedly a huge contribution to employment in many developing countries where there is a challenge of high unemployment and poverty exists.

In Ethiopia, like any other developing countries, MSE has become an increasingly widespread used strategy for its labor intensiveness, suitability to produce more jobs with less capital per job created, its utilization of locally available resources, fostering of linkage within and among various sectors and its resilience to internal and external economic shocks (FMSEDA, 2012).

Within the Ethiopian context, despite the potential contribution of the MSE to poverty reduction and employment creation is widely recognized, the Government until very recently had not extended adequate support to the development of the sector. Recent research work by (G. Gizbher \& Ayenew, 2010) indicated that in Ethiopia there has not been an independent assessment of the contribution of the MSE development strategy to poverty 
reduction, job creation and business growth either at the federal or regional levels to date. Thus, this paper try to assess the different policy, financial and operational factors constraining the growth and continuity of micro and small enterprise in Robe town .

\section{CONCEPTUAL FRAMEWORK}

The conceptual framework shows relationships between independent and dependent variables. Since business growth and continuity is influenced by both internal and external factors operators need to understand what influence businesses to reach expected performance. external factors includes finance factors, marketing factors, workings premises factors, infrastructure factors and internal factors such as management and entrepreneurial philosophy is the main factors that influence for the success and the failure of any business organizations.

In line with the study objectives was increasing the growth and continuity of MSEs, which measured interims of profit, capital and number of employees, were dependent variable whereas the external and internal factors affecting MSE performance were used as independent variables. Such factors includes: political, legal, finance, marketing, work premise, technology, infrastructure, opportunity seeking, persistence, commitment to the work, demand for efficiency and quality, risk taking, goal setting, systematic planning and monitoring, information seeking, persuasion and networking, self-confidence .Admasu (2012).

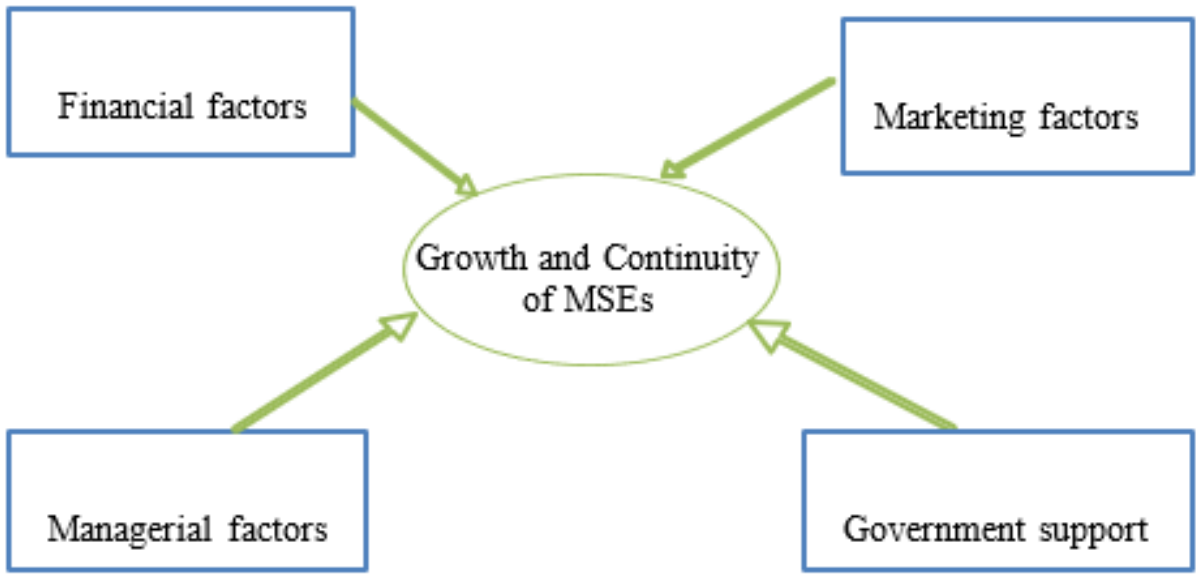

Source:-the researcher own construction

\section{METHODOLOGY}

\section{Research Design}

The main objective of this study is to identify the problems related to the growth and continuity of Micro and Small enterprises in Robe town. In order to achieve these objectives the researcher was used, explanatory research design and descriptive research design .

The study gathered qualitative data and quantitative data from employees and owners of small business operating in Robe town. Majority of the data sought was mainly quantitative. This is because quantitative data is always number-based and usually less in-depth but more breadth of information across cutting a large number of cases.

\section{POPULATION}

The Target population for this research was drawn from Micro and small enterprises operating in Robe town which are not homogeneous in nature. The study targeted 949 Micro and small enterprise in Robe town comprising of construction, Manufacturing, Service, Trade, and Urban agriculture.

\section{SAMPLING AND SAMPLING TECHNIQUE}

Sampling frame describes a complete list of all the cases in the target population from which the researcher draws a sample (Saunders et al., 2016). The sample frame was organized into a relatively homogeneous group (Strata's), before selecting elements for the sample.The strata's were sectors of MSEs including construction, Manufacturing, Service, Trade, and Urban agriculture.

To select sample of enterprise from the total population of MSEs a stratified random sampling was applied to get a representative number of enterprise from each sector that was considered in this study this technique was preferred because, small and micro enterprises of Robe town have different income, budget and sector under its supervision from all micro and small enterprise.

In this case, it involved the classification of MSEs according to the different trade areas which were construction, Manufacturing, Service, Trade, and Urban agriculture. Within each strata or trade area, individual 
owner managers were picked using simple random sampling. Stratified random sampling method was used to ensure that a representative sample from the different trade areas was used to conduct the study.

\section{SAMPLE SIZE}

The sample for this study consisted of owner and managers of MSEs in responding the questionnaires Samples was selected as representative of the total population was distributed to randomly for a total of MSEs according their strata after their stratification in to their homogenous sectors categorizing in different sectors.

Accordingly, from this total population the sample size was proposed by using the following Sample size determination formula provided by Yamane (1967) by using 95\% confidence level with the 5\% precision.

The following equations applied

$\mathrm{n}=\frac{\mathrm{N}}{1+\mathrm{N} *} 2$

Where,

$\mathrm{n}=$ sample size

$\mathrm{N}=$ the total size of population

$\mathrm{e}=$ acceptable sampling error, $95 \%$ confidence level with 5\% precision. Accordingly, the sample is determined as follows

Total population $=949$

$\mathrm{n}=\frac{949}{1+949 *(0.05)} 2 \quad$ sample size $=281$

Table 3.1 major activities in the town and respective sample size

\begin{tabular}{|l|l|l|l|}
\hline Major activities & Targeted population & Sampling percentage & Sample size \\
\hline Construction & 292 & $30.77 \%$ & 86 \\
\hline Manufacturing & 183 & $19.28 \%$ & 54 \\
\hline Service & 188 & $19.81 \%$ & 56 \\
\hline Trade & 161 & $16.97 \%$ & 48 \\
\hline Urban agriculture & 125 & $13.17 \%$ & 37 \\
\hline TOTAL & 949 & $100 \%$ & 281 \\
\hline
\end{tabular}

Source: Robe town trade and industry bureau (2019)

\section{METHOD OF DATA COLLECTION}

According to Cooper and Schindler (2014), data collection method is the gathering of data for purposes of analyzing so as to make inferences from the data. The study employed both primary and secondary sources of data collection. The primary data was obtained by preparing and distributing structured questionnaire. The secondary data was collected from different books, internet, office manuals, and other printed materials.

\section{DATA ANALYSIS}

The results were analyzed and interpreted using statistical package for social science (SPSS) version 22. As result, descriptive and inferential analyses were conducted by employing different methods. In descriptive statistics mean values, frequencies and standard deviations of the respondent's answers were calculated. In inferential Cronbach's Alpha test takes place to assure reliability of the items. Simple regressions and correlation analysis was also used to analyze the impact and the relationship between the dependent and independent variables.

Before analysis of the data collected using primary sources they were checked for accuracy, utility and completeness, compatibility with the purpose of the study.

For the purpose of reducing chance of confusion of questionnaires and ensuring those for validity and correctness some pilot tests were taken by distributing the questionnaires for 23 owners or managers and some irrelevant and redundant questions were reduced before actual distribution of the questionnaires.

The data gathered through closed- ended questionnaires were analyzed and presented using descriptive statistics, through figures, graphs, tables and percentages. And the data collected through open-ended questionnaires also analyzed qualitatively by supporting the quantitative analysis. The data gathered by using both descriptive and inferential statistics. Descriptive statistics: such as frequencies, percentages, means and standard deviations was used to summarize and present the data. Inferential statistics; Pearson correlation coefficient were used to show the interdependence between the independent and dependent variables.

\section{VALIDITY AND RELIABILITY \\ VALIDITY}

Validity is the degree to which a test measures what it purports to measure (Creswell, 2009). Validity is defined as the accuracy and meaningfulness of the inferences which are based on the research results. It is the degree to which results obtained from the analysis of the data actually represents the phenomena under study. He contends that the validity of the questionnaire data depends on a crucial way the ability and willingness of the respondents 
to provide the information requested.

Questionnaires was tested on potential respondents to make the data collecting instruments objective, relevant, suitable to the problem and reliable as recommended by (John A. et al., 2007). Issues raised by respondents are corrected and questionnaires were refined. Besides, proper detection by advisor was also taken to ensure validity of the instruments. Finally, the improved version of the questionnaires were printed, duplicated and dispatched.

It can clearly address how these factors affect the growth of MSEs in Robe town. The relevant data was collected on the factors constraining the growth of MSE. This can better to indicate the relationship between factors and the growth of MSE. Moreover, to have valid conclusion, inferential statistical model was used to test the relationship between variables.

\section{RELIABILITY}

The reliability of instruments measures the consistency of instruments. (Creswell, 2009) considers the reliability of the instruments as the degree of consistency that the instruments or procedure demonstrates. The reliability of a standardized test is usually expressed as a correlation coefficient, which measures the strength of association between variables. Such coefficients vary between -1.00 and +1.00 with the former showing that there is a perfect negative reliability and the others shows that there is perfect positive reliability.

In this study, each statement rated on a 5 point Likert response scale which includes strongly agree, agree, neutral, disagree and strongly disagree.

Table 3.2 Reliability Statistics

\begin{tabular}{|l|l|l|l|}
\hline No & Dimension & Number of items & Alpha Value \\
\hline 1 & Marketing & 6 & 0.842 \\
\hline 2 & Financial & 5 & 0.848 \\
\hline 3 & Management & 4 & 0.889 \\
\hline 4 & Government support & 5 & 0.915 \\
\hline 5 & Continuity and Growth & 3 & 0.912 \\
\hline
\end{tabular}

Source: Researcher's own Survey

Therefore, the Cronbach's alpha for this study collected from 23 randomly selected respondents for the 5 items included in this study are 0.881 . This shows that the Cronbach's alpha lies within the 0.88 category indicating that the survey instrument was good in terms of internal consistency. Validity is concerned with meaningfulness of research component. The validity of the research was assured through designing appropriate questions for the questionnaire. Since, instruments were developed based on research questions and objectives; it is possible to collect necessary data from respondents. Then, instruments are consistent with the objectives of the study. Since, instruments were developed based on research questions and objectives; it is possible to collect necessary data from respondents. Then, instruments are consistent with the objectives of the study.

\section{DATA ANALYSIS, INTERPRETATION AND FINDINGS}

The Questionnaires were the tools selected and used throughout the analysis of the data using SPSS. To collect the data through questionnaire, 281 questionnaires were distributed to MSEs in Robe town and 259 of questionnaires were returned back with completely filled and significant responses. The returned questionnaires have 259 response rates and hoped sufficient to analyze the data with it. The data was analyzed using descriptive statistics with figures and tables using frequency, percentage, mean and standard deviation.

\section{Demographic Data}

Table 4.1.1.Gender of the respondents

\begin{tabular}{|c|c|c|c|c|}
\hline \multicolumn{5}{|c|}{ sex of respondents } \\
\hline & & Frequency & Percent & Valid Percent \\
\hline \multirow[t]{3}{*}{ Valid } & Male & 167 & 64.5 & 64.5 \\
\hline & Female & 92 & 35.5 & 35.5 \\
\hline & Total & 259 & 100.0 & 100.0 \\
\hline
\end{tabular}

Source: Own survey (2019)

As it is depicted in table 4.1.1, majority of the respondents or $167(64.5 \%)$ of the enterprise owners or managers are males and the remaining 92(35.5) are females. This may show significant proportion of the participants in the micro and small enterprises are men. 
Table 4.1.2.age of the respondents

\begin{tabular}{|c|c|c|c|c|c|}
\hline \multicolumn{6}{|c|}{ age of respondents } \\
\hline & & Frequency & Percent & Valid Percent & $\begin{array}{l}\text { Cumulative } \\
\text { Percent }\end{array}$ \\
\hline \multirow[t]{6}{*}{ Valid } & $18-25$ & 35 & 13.5 & 13.5 & 13.5 \\
\hline & $26-30$ & 119 & 45.9 & 45.9 & 59.5 \\
\hline & $31-35$ & 79 & 30.5 & 30.5 & 90.0 \\
\hline & $36-40$ & 22 & 8.5 & 8.5 & 98.5 \\
\hline & ABOVE 40 & 4 & 1.5 & 1.5 & 100.0 \\
\hline & Total & 259 & 100.0 & 100.0 & \\
\hline
\end{tabular}

Source: Researcher's survey (2019)

As it is presented in Table 4.1.2, the researcher divided respondents' age into four age groups ranging 18-40 years. Accordingly, 119 (45.95\% )of the respondents fall between 26-30 years old, whereas, 79 or 30.50 percent of respondents' age is between 31-35 years, also, 35(13.51)of the respondents fall between 18-25 years old, whereas 22 or 8.49 percent of respondent's age is between 36-40 years and 4 or 1.54 percent of them have above 40 years age. This shows the majority of respondents are between ages of 26 and 35 years. This confirms that all respondents were young and they can understand the purpose of the research.

Table 4.1.3 Education level of the respondents

Education level of respondents

\begin{tabular}{|l|l|l|l|l|l|}
\hline \multicolumn{2}{|c|}{} & Frequency & Percent & Valid Percent & $\begin{array}{l}\text { Cumulative } \\
\text { Percent }\end{array}$ \\
\hline \multirow{4}{*}{ Valid } & High school & 12 & 4.6 & 4.6 & 4.6 \\
\cline { 2 - 6 } & Certificate & 65 & 25.1 & 25.1 & 29.7 \\
\cline { 2 - 6 } & Diploma & 63 & 24.3 & 24.3 & 54.1 \\
\cline { 2 - 6 } & First degree & 110 & 42.5 & 42.5 & 96.5 \\
\cline { 2 - 6 } & second degree and above & 9 & 3.5 & 3.5 & 100.0 \\
\cline { 2 - 5 } & Total & 259 & 100.0 & 100.0 & \\
\hline
\end{tabular}

Source: Researcher's own Survey (2019)

As Table 4.1.3 indicates regarding to educational qualification, 12 or 4.63 percent of the

Respondents' education is high school, 65(25.10) of them are Certificate, 63(24.32\%) had graduated in diploma, 110or 42.47 percent are first degree holder and 9or 3.47 percent are second degree. Therefore, data collection procedures used in this study were based on the response that the respondents were literate and exhibited basic know how of the purpose and the importance of the research thus would voluntarily act as the respondents in the study. As sex, age and educational qualification of individuals are different; individuals also differ in their work experience durations. Respondents were asked to indicate the experience year they have in business activities and the data collected shows on the following table.

4.1.4 Year of experience of participants

\begin{tabular}{|l|l|l|l|l|l|}
\hline \multicolumn{2}{|l|}{ Experience of respondents } & Frequency & Percent & Valid Percent & Cumulative Percent \\
\hline \multirow{4}{*}{ Valid } & $1-3$ years & 109 & 42.1 & 42.1 & 42.1 \\
\cline { 2 - 6 } & 4- 6 years & 91 & 35.1 & 35.1 & 77.2 \\
\cline { 2 - 6 } & $7-10$ years & 44 & 17.0 & 17.0 & 94.2 \\
\cline { 2 - 6 } & above 11 years & 15 & 5.8 & 5.8 & 100.0 \\
\cline { 2 - 6 } & Total & 259 & 100.0 & 100.0 & \\
\hline
\end{tabular}

Source: Researcher's own survey (2019)

As Table 4.1.4 indicates, most of the respondents surveyed (109 participants or 42.1 percent) have 1-3years of experience, 91(35.1 percent) of them have 4-6, 44(24.1 percent) have 7-10 and 15(5.8) have more than 11 years of experience in the enterprises. Even though individuals can learn more from their experience that can help them to predict and flexible according the opportunities in the environment, can learn more from the colleagues in planning and in creating relationship with society customers consuming their products, most respondents of MSEs have 1-3 years in which their experience of year has impact on their business where many studies indicates there is relationship between experience and business performance. 
Table 4.2.1Descriptive Statistics of Marketing Constraints

\begin{tabular}{|l|l|l|l|l|}
\hline S/N & \multicolumn{1}{|l|}{ Variable } & N & Mean & $\begin{array}{l}\text { Std. } \\
\text { Deviation }\end{array}$ \\
\hline 1 & There are market information and demand forecasting practices. & 259 & 3.5058 & 1.14922 \\
\hline 2 & Searching new market for my products is easy. & 259 & 2.1931 & .91995 \\
\hline 3 & Lack of setting clear and competitive price for products. & 259 & 2.5174 & 1.06143 \\
\hline 4 & There is good creating awareness for customers about the product. & 259 & 2.9768 & 1.16116 \\
\hline 5 & Lack of promotion to attract potential customers. & 259 & 2.9112 & 1.14958 \\
\hline 6 & Lack of continuous improvement of product & 259 & 3.6409 & 1.21618 \\
\hline 7 & $\begin{array}{l}\text { There are good relationship with an organization that conduct } \\
\text { marketing research }\end{array}$ & 259 & 3.1737 & 1.27161 \\
\hline 8 & The society's attitude towards my Products/ services is positive. & 259 & 2.6409 & 1.10602 \\
\hline 9 & Market potential of my products is promising. & 259 & 2.7336 & 1.22414 \\
\hline & GROUP MEAN & 259 & 2.92 & .36892 \\
\hline
\end{tabular}

Source: Researcher's own survey (2019)

As mentioned above constraining factors of the growth of the firm were taken using the group mean value as stepping stone and marketing constraint which its mean value is lower than the group mean value was categorized as low effect on the growth, and which its mean value is equal or greater but not far from group mean are categorized moderate. The marketing constraints having mean value of greater than group mean were taken as the major marketing constraints affecting the MSEs. Generally variables with low mean value indicates low effect in constraining the firm's growth, moderate value was medium with effects and variables with high value have high effect in constraining the firms' growth. According to the marketing constraints indicated on Table 4.1 lack of Searching new market (2.1931), Lack of setting clear and competitive price for products. (2.5174), Negative society's attitude (2.6409), and Lack of market potential (2.7336) are variables with low mean value compared with group mean.

The moderate marketing constraint is Lack of promotion to attract potential customers (2.9112), and Lack of good creating awareness for customers about the product (2.9768).

The other marketing constrains indicating high mean value are lack of good relationship with an organization that conduct marketing research (3.1737), lack of market information and demand forecasting practices.(3.5058) and Lack of continuous improvement of product (3.8077).

The findings suggest that Marketing factor is a major challenge on the growth of micro and small Enterprises in the study area.

Table 4.2.2 Descriptive Statistics of Financial Constraints

\begin{tabular}{|c|c|c|c|c|}
\hline $\mathrm{S} / \mathrm{N}$ & Variable & $\mathrm{N}$ & Mean & Std. Deviation \\
\hline 1 & The Credit institutions are sufficient to access loans easily. & 259 & 3.2046 & 1.46027 \\
\hline 2 & $\begin{array}{l}\text { The interest rate charged by banks and other lending institutions } \\
\text { are reasonable }\end{array}$ & 259 & 2.8571 & 1.33195 \\
\hline 3 & Lack of cash management skills. & 259 & 2.5212 & 1.08662 \\
\hline 4 & $\begin{array}{l}\text { The Loan application procedures of banks and other lending } \\
\text { institutions are not complicated. }\end{array}$ & 259 & 3.3320 & 1.33736 \\
\hline 5 & Lack of sufficient working capital. & 259 & 3.5714 & 1.15374 \\
\hline 6 & $\begin{array}{l}\text { Collateral requirement from banks and other lending } \\
\text { institutions are reasonable for my business }\end{array}$ & 259 & 3.3475 & 1.37069 \\
\hline 7 & $\begin{array}{l}\text { There is good management of Current Assets (like inventory, } \\
\mathrm{A} / \mathrm{R} \text { ). }\end{array}$ & 259 & 2.7143 & 1.23083 \\
\hline & GROUP MEAN & 259 & 3.0783 & .46164 \\
\hline
\end{tabular}

Source: Researcher's own survey (2019)

As mentioned above constraining factors of the growth of the firm were taken using the group mean value financial constraint which its mean value is lower than the group mean value was categorized as low effect on the growth, and which its mean value is equal or greater but not far from group mean are categorized moderate.

The financial constraints having mean value of greater than group mean were taken as the major financial constraints affecting the MSEs. Generally variables with low mean value indicates low effect in constraining the firm's growth, moderate value was medium with effects and variables with high value have high effect in constraining the firms' growth.

Regarding to financial constraints indicated on Table 4.2.2Lack of cash management skills (2.5212) and Lack of good management of Current Assets. (2.7143) are variables with low mean value compared with group mean. The moderate marketing constraint is interest rate charged by banks and other lending institutions 2.8571). 
The other financial constrains indicating high mean value are insufficient Credit institutions to access loans easily (3.2046), The Loan application procedures of banks and other lending institutions.( 3.3320), Collateral requirement from banks and other lending institutions(3.3475) and Lack of sufficient working capital (3.5714).From this result, it is possible to say that financial factors contributed for hindering the growth and survival of MSES in the study area. This indicates the limitation /absence of finance affects the growth of enterprises.

Table 4.2.3 Descriptive Statistics of Management Constraints

\begin{tabular}{|l|l|l|l|l|}
\hline S/N & VARAIABLE & N & Mean & Std. Deviation \\
\hline 1 & $\begin{array}{l}\text { There are clear division of duties and responsibility among } \\
\text { employees in the firm. }\end{array}$ & 259 & 3.4981 & 1.19227 \\
\hline 2 & Lack of well trained and experienced employees. & 259 & 3.3205 & 1.33295 \\
\hline 3 & The employee handling practice is adequate and proper. & 259 & 3.1583 & 1.21762 \\
\hline 4 & Lack of management ability in creating external relationship. & 259 & 3.8108 & .99948 \\
\hline 5 & The communication in the firm is effective. & 259 & 2.8147 & 1.13627 \\
\hline & GROUP MEAN & 259 & 3.3205 & .51036 \\
\hline
\end{tabular}

Source: Researcher's own survey (2019)

According to Table 4.2.3 shows, the respondents' response summarized in mean value of variables of management constraints and the group mean value is 3.3205 helps as bench mark in categorizing the variables effect in constraining the growth of the firms. For variables whose means is less than 3.3 were taken as variables having less effect, variables around 3.3 or approximate to the group mean value was take as moderate in affecting the growth and those variables whose mean value is greater than the group mean value affect the growth of the firm at higher level.

Accordingly lack of communication in the firm (2.8147), lack of employee handling practice (3.1583) has low mean value than group mean and also their effects are considered as low.

On the other hand, Lack of well trained and experienced employees (3.3205) moderate mean value and the rest of them are with higher power in influencing the growth like lack of clear division of duties and responsibility among employees in the firm (3.4981), Lack of management ability in creating external relationship (3.8108). Table 4.2.4 Government Support Descriptive Statistics

\begin{tabular}{|l|l|l|l|l|}
\hline S/N & Variable & N & Mean & $\begin{array}{l}\text { Std. } \\
\text { Deviation }\end{array}$ \\
\hline 1 & $\begin{array}{l}\text { There are well of business development services (supporting } \\
\text { institutions). }\end{array}$ & 259 & 3.4015 & 1.27929 \\
\hline 2 & There is bureaucracy in company registration and licensing & 259 & 3.6641 & 1.06344 \\
\hline 3 & There is adequate arrangement of required infrastructures. & 259 & 3.3012 & 1.25524 \\
\hline 4 & Lack of providing right business location & 259 & 2.9421 & 1.23911 \\
\hline 5 & Adequate government's effort in changing public attitude. & 259 & 2.8958 & 1.25474 \\
\hline 6 & $\begin{array}{l}\text { Lack of providing training and skill upgrading for MSE manager or } \\
\text { owner. }\end{array}$ & 259 & 3.4093 & 1.26156 \\
\hline & GROUP MEAN & 259 & 3.2690 & .45625 \\
\hline
\end{tabular}

Source: Researcher's own survey (2019)

As a result, the Group Mean Value of 3.2690 was taken as a benchmark to keep apart the factors having low, moderate and high effect on the enterprises normal operation by matching the lowest value with indicating the lowest negative effect on firms' growth and others follow accordingly. Consequently, lack of government's effort in changing public attitude,(2.8958) and Lack of providing right business location (3.5897) have lesser mean value and relatively have less effect. In contrast, bureaucracy in company registration and licensing indicates the highest mean value in which it has considered as potential effect on the growth of the enterprises (3.6641) and Lack of providing training and skill upgrading for MSE staffs 4.2436. Even though the mean values of government's procurement and training and skill upgrading have high mean value compared with other variables used in this study, they are relatively lower than the two variables indicated in this government support related constraints Table 4.2.5 Continuity and growth of MSEs

\begin{tabular}{|l|l|l|l|l|}
\hline $\mathrm{S} / \mathrm{N}$ & Variable & $\mathrm{N}$ & Mean & Std. Deviation \\
\hline 1 & The growth of our business profit is satisfactory & 259 & 2.2278 & 1.07754 \\
\hline 2 & Our capital is growing well as we expect. & 259 & 2.1544 & .91462 \\
\hline 3 & We are satisfied with the Growth in sales of products and/or services. & 259 & 2.1042 & .89829 \\
\hline 4 & We are satisfied in our operational efficiency. & 259 & 2.1622 & .94662 \\
\hline & GROUP MEAN & 259 & 2.1622 & .53352 \\
\hline
\end{tabular}

Source: Researcher's own survey (2019) 
According to table 4.2.5 shows, the respondents' response summarized in mean value of continuity and growth of MSEs and the group mean value is 2.1622 . For the growth of micro and small business enterprise whose means is less than 2.1622 were taken as having high effect, variables around 2.1 or approximate to the group mean value was take as moderate in affecting the growth and those variables whose mean value is greater than the group mean value affect the growth of the firm at lower level. Accordingly we are satisfied with the Growth in sales of products and/or services (2.1042) and our capital is growing well as we expect (2.1544) has low mean value than group mean .This means the firm capital and the sale growth of the MSES in Robe town is not growing as their expect.

On the other hand, we are satisfied in our operational efficiency (2.1622) and the growth of our business profit is satisfactory (2.2278) moderate mean value and also the firm is not satisfied with their operational efficiency Table 4.3.1:-The relationship between independent variables and survival and growth Correlations

\begin{tabular}{|ll|l|l|l|l|l|}
\hline & & & & & growth \\
continuity
\end{tabular}

**. Correlation is significant at the 0.01 level (2-tailed).

Source: Researcher's own survey

As it is clearly indicated in the above Table 4.3.1, a strong positive relationship was found between management factor and continuity and growth $(\mathrm{r}=0.625, \mathrm{p}<.01)$, and marketing and survival $(\mathrm{r}=0.564, \mathrm{p}<.01)$, which are statistically significant at $95 \%$ confidence level.

Moreover, the table presents the association between the selected variables and continuity and growth of small scale enterprises for a sample of 281 small scale enterprises in Robe town.

There is substantial, however statistically significant relationship between government support factors and continuity and growth $(\mathrm{r}=0.549, \mathrm{p}<.01)$. The result on table above further indicates that, there is a substantial positive correlation between financial and survival $(\mathrm{r}=0.546, \mathrm{p}<.01)$, which is statistically significant at $95 \%$ confidence level. This implies that SEs with financial performed considerably better.

\section{MULTICOLLINEARITY}

For this study the researcher was checked this assumption with tolerance and VIF statistics. Andy (2006) suggests that a tolerance value less than 0.1 almost certainly indicates a serious colinearity problem. Liu (2010) also suggests that a VIF value greater than 10 because for concern and in these research data the values are below 10 for all predictors 
Table 4.3.3 multi collinearity Model Test Table

\begin{tabular}{|l|l|l|l|}
\hline \multicolumn{2}{|l|}{ Model } & Collinearity Statistics \\
\cline { 3 - 4 } \multicolumn{2}{l|}{} & Tolerance & VIF \\
\hline \multirow{3}{*}{1} & MARKET & .614 & 1.629 \\
\cline { 2 - 4 } & FINANCE & .646 & 1.547 \\
\cline { 2 - 4 } & MANAGEMENT & .555 & 1.803 \\
\cline { 2 - 4 } & GOVERNMENT & .650 & 1.538 \\
\hline \multicolumn{2}{|l}{ A. Dependent variable: survival } \\
\hline
\end{tabular}

Source: - Own survey result (2019)

For the current model the VIF values are all well below 10 and the tolerance statistics all well above 0.2; therefore, we can safely conclude that there is no collinearity with in data.

\section{NORMALITY TEST}

Table 4.3.2 Normality Model test table

\begin{tabular}{|l|l|l|l|l|l|l|}
\hline \multicolumn{2}{|l|}{} & Market & Finance & Management & Government & Continuity \\
\hline \multirow{2}{*}{ Valid } & 259 & 259 & 259 & 259 & 259 \\
\cline { 2 - 7 } & Missing & 0 & 0 & 0 & 0 & 0 \\
\hline Skewness & .694 & .837 & 1.106 & .651 & 1.749 \\
\hline $\begin{array}{l}\text { Std. Error of } \\
\text { Skewness }\end{array}$ & .151 & .151 & .151 & .151 & .151 \\
\hline Kurtosis & .115 & .462 & .529 & .324 & 2.861 \\
\hline Std. Error of Kurtosis & .302 & .302 & .302 & .302 & .302 \\
\hline
\end{tabular}

Source: - Own survey result (2019)

TABLE 4.3.4 ANOVA RESULTS

ANOVA $^{\mathrm{a}}$

\begin{tabular}{|ll|l|l|l|l|l|}
\hline Model & & Sum of Squares & Df & Mean Square & F & Sig. \\
\hline 1 & Regression & 112.624 & 4 & 28.156 & 70.665 & $.000^{\mathrm{b}}$ \\
& Residual & 101.205 & 254 & .398 & & \\
& Total & 213.829 & 258 & & & \\
\hline
\end{tabular}

Source: Researcher's own survey (2019)

a. dependent variable: continuity and growth

b. predictors: (constant), Government, Market, Finance, Management

As indicated in table 4.3.4 there is statistically significant effect between independent variable(Marketing, Management, Finance and Government ) and dependent variable (Growth and continuity ) where, (F) value was (70.665) at 0.000 which states that there is significant effect of independent and dependent variable.

TABLE 4.3.5 COEFFICIENTS RESULT

\begin{tabular}{|c|c|c|c|c|c|c|}
\hline \multicolumn{7}{|c|}{ COEFFICIENTS $^{\mathrm{A}}$} \\
\hline \multicolumn{2}{|c|}{ Model } & \multicolumn{2}{|c|}{ Unstandardized Coefficients } & \multirow{2}{*}{$\begin{array}{l}\text { Standardized } \\
\text { Coefficients } \\
\text { Beta }\end{array}$} & \multirow[t]{2}{*}{$\mathrm{T}$} & \multirow[t]{2}{*}{ Sig. } \\
\hline & & $\mathrm{B}$ & Std. Error & & & \\
\hline \multirow[t]{5}{*}{1} & (Constant) & .101 & .117 & & .862 & .389 \\
\hline & MARKET & .169 & .044 & .211 & 3.817 & .000 \\
\hline & FINANCE & .171 & .047 & .196 & 3.637 & .000 \\
\hline & MANAGMENT & .238 & .046 & .298 & 5.140 & .000 \\
\hline & GOVERNMENT & .163 & .042 & .208 & 3.898 & .000 \\
\hline
\end{tabular}

Source: Researcher's own survey (2019)

Table 4.3.5 further shows that, all the explanatory variables included in this study significantly explain at $95 \%$ confidence level to the variation on the dependent variable. The standardized beta coefficient column shows the contribution that an individual variable makes to the model. The beta weight is the average amount the dependent variable increases when the independent variable increases by one standard deviation. As these are standardized we can compare them.

Market factors: market factors are statistically significant at 5\% significant level. The influence on the Growth and continuity of Micro and small enterprises is from the independents variables is marketing factors $(0.169$, $\mathrm{P}<0.01)$. The regression result clearly shows that there is significant and positive relationship with the growth and continuity of micro and small enterprise Thus, enterprises with access to market have promote significantly 
but, enterprises with market problem or limited access to market have less chance of promote or their potential is likely to decrease. Marketing problems include inadequacy of market, difficulty of searching new market, lack of demand forecasting, lack of market information and absence of relationship with an organization/association that conduct marketing research.

Finance factors: The other variable in this study which is expected to create variation on the Growth and continuity of enterprises is financial factors $(0.171, \mathrm{p}<0.01)$, shows there is significant relationship with Growth and continuity of micro and small scale enterprises. Based on the regression result, the null hypothesis which states that there is significant relationship on the Growth of enterprises in relation to the difference in access to finance is accepted.

Micro and small enterprise which have access to finance promote better than those which have no access to finance or credit. For various reasons ranging from a lack of collateral to bias against small enterprises, Small enterprises tend to face greater financial constraints than do larger enterprises.

Small enterprises which have access to credit promote better than those which have shortage of capital or credit and solving this problem leads to solution of promote.

Management factors: Is statistically role play. The regression output shows that experience of manager or owner of the enterprise $(0.238, \mathrm{p}<0.01)$, has a significant relationship with growth and survival of micro and small scale enterprises. This would imply that, the more access management the better growth and continuity of micro and small enterprises than others. Small enterprises have management problem no more chance of promote to next stage in the case of management problems. These problems may include Lack of clear division of duties and responsibility among employees, Poor and ineffective communication, Lack of strategic business planning, Lack of well trained and experienced employees and Shortage of accessible training facilities.

Government support factors: Government factors are statistically significant at 5\% significant level. The influence on the growth and continuity of micro and small scale enterprises is from the independents variables is Government factor $(0.163), \mathrm{P}<0.01$. Thus, small enterprises with access to Government support have promoted significantly but, small enterprises with Government support problem have less chance of promote to medium enterprises.

\section{CONCLUSION}

Based on the results of this study, different factors were identified as responsible for hindering MSE growth and continuity in Robe town. To give conclusion for these factors, the researcher combined strongly agrees and agree responses together and strongly disagrees and disagree in one for the purpose of using percentage.

The result show that, the respondents' profile indicates male's respondents in small enterprises is 64.5 percent compared females. The age of most respondents 45.95 percent fall within the range of 26-30 years. Most of small enterprises respondent educational qualification is in First degree indicating 46.3 percent. As the findings marketing factors affecting small enterprises from the findings indicate a strong positive relationship was found between marketing factor and Growth and survival $(0.169, \mathrm{P}<0.01)$.

When there is limited market access, the probability that MSEs experience growth is less in which limited customers coupled. Lack of knowledge related to marketing strategies, mixes, information, lack of adaptation to changing environment and networks with successful businesses and knowledgeable persons are other factors related to marketing constraints. Lack of product improvement especially MSEs in the same sector sell identical products without any additional distinctiveness, innovative activities and modification and this lack made similar products without matching their products as there is change in demand and flexibility with environment. Thus, since marketing is one of the most activities required by businesses to growth through satisfying the needs and wants of customers, its constraints on the other hand hinders the growth of firms.

Financial factors and growth and continuity $(0.171, \mathrm{p}<0.01)$, has a significant relationship with growth and continuity of micro and small scale enterprises. The limitations and complexities of obtaining loans from financial institutions were cited as major hindrances to small business development and most MSEs are unable to secure badly needed loans from the financial institutions. Collateral requirement to get loan these institutions is required highly and it is beyond their capacity and business.

On the other hand, the loans provided by the institution are small and short repayment period. Due to this MSEs forced to rely and use other informal sources like self-financing or borrowing from friends which are short term finance, costly and risky. Financial constraints limit the number of preferable alternatives that can be considered and force them to use inappropriate technology \& others because it is the only one they can afford. This limited growth and continuity of MSEs. The result of study a substantial positive correlation between management factors and growth and continuity $(0.238, \mathrm{p}<0.01)$, has a significant relationship with growth and continuity of micro and small scale enterprises.

Lack of multi- skill training of employees, lack of well -rounded experience in basic business activities and lack of management ability in creating external relationship are the major factors affecting the growth of MSEs. Government support factors and growth and continuity $(0.163), \mathrm{P}<0.01$, Thus, small enterprises with access to 
Government support have promoted significantly but, small enterprises with Government support problem have less chance of promote to medium enterprises.

On the other hand, various governmental bodies designed various programs aimed at developing small enterprises sectors. Since good infrastructure has the effect of promoting MSEs by lowering the cost of doing business, lack of key and adequate infrastructure related to adequate supply of electrical power, access to roads, water and sewerage, telecommunications can directly or indirectly lag the growth of businesses behind.

\section{REFERENCES}

Abera,A.(2012).Factors Affecting the Performance of Micro and Small Enterprises in Arada and Lideta Sub-Cities, Addis Ababa.

Addis ReMSEDA (2009a), Micro and Small Enterprises Development Achievement in Addis Ababa, Addis Ababa: Addis Ababa Trade and Industry Bureau.

Bradley, D.B. \&Cowdery, C. 2002. Small business: Causes of bankruptcy.

Borg, J. \& Gall, L. (2013). Applying Educational Research: How to Read, do and Use Research to Solve Problems of Practice.

Bolton, S. \& Thompson, K. (2011). SMEs Governance Mechanisms Practices and Financial Performance.Journal of Business and Management.

Carree, M. A. \&Thurik, R. (1998). Small Firms and Economic Growth in Europe, AtlanticEconomic Journal.

Demeke,T.,(2016 ). Assessment of Challenges and Opportunities of Women Owned Micro and Small Enterprises: A Case of Asella Town. Research Journal of Finance and Accounting.

Duncan Cramer and Dennis Howitt. 2004. A Practical Resource for Students in the Social Sciences. The SAGE Dictionary of Statistics.London, Sage Publications.

Gebretinsae, K. (2013). Dilemma Facing Enterprises in Kenya.A journal of Economic review.

ILO, (2015) Small and Medium -Size enterprise and decent an productive employment creation International Labour conference report 104th Session, (2015).

Ishengoma, E. (2004): The Role of Firm-Resources: Performance Differentials Between Women and Men owned Micro-enterprises in Tanzania, Leipzig: University of Leipzig Papers on Africa. 